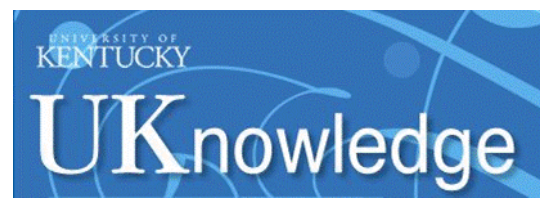

University of Kentucky

UKnowledge

\title{
Patient Characteristics Associated with Inpatient Psychiatric Re- admissions and the Utility of the READMIT Clinical Risk Index
}

Autumn P. Roque

University of Kentucky, autumn.roque@hotmail.com

Right click to open a feedback form in a new tab to let us know how this document benefits you.

\section{Recommended Citation}

Roque, Autumn P., "Patient Characteristics Associated with Inpatient Psychiatric Re-admissions and the Utility of the READMIT Clinical Risk Index" (2016). DNP Projects. 74.

https://uknowledge.uky.edu/dnp_etds/74

This Practice Inquiry Project is brought to you for free and open access by the College of Nursing at UKnowledge. It has been accepted for inclusion in DNP Projects by an authorized administrator of UKnowledge. For more information, please contact UKnowledge@lsv.uky.edu. 
Patient Characteristics Associated with Inpatient Psychiatric Re-admissions and the Utility of the READMIT Clinical Risk Index

Autumn P. Roque

\author{
University of Kentucky \\ College of Nursing
}

Spring 2016

Peggy El-Mallakh, PhD, RN- Committee Chair

Zim Okoli, PhD, MPH, MSN, RN- Clinical Mentor

Jan Findlay, PhD, MSN, APRN- Committee Member 


\section{Dedication}

I would like to dedicate this final work to my family and friends. I love you all. I had a lot of people looking out for me and working to help me find a way to maintain my studies throughout the program. A special note to my mother who put her life on hold to help me with the kids. Without her help, I would not have been able to complete this project or my clinical rotations. Mimi is the best. I love you, Mom. 


\section{Acknowledgements}

I would like to thank Dr. Peggy El-Mallakh and Dr. Pat Howard for being my first mentors in graduate education. These ladies spoke to me about pursuing graduate education seven years ago and I am grateful to have had the opportunity to be a part of their program and to share their passion in caring for persons with mental illness. Dr. Billy Mullins was my first unit manager as a bedside nurse, and he found a way to support my pursuit of graduate studies while I maintained a fulltime work schedule the first three years of this program. He also taught me much about leadership. Thank you, Billy.

A special thank you to Whitney Kurtz-Ogilvie and Dr. Debra Anderson. It is still difficult for me to put into words how much Dr. Anderson's support and belief in my abilities means to me, so let me just say, "Thank you". I worked closely with Whitney throughout the program and know that I would not have had the success with my written work had it not been for her expertise. Thank you, Whitney.

Dr. Jan Findlay and Dr. Zim Okoli have been tremendous mentors and committee members. Dr. Findlay paved the way for my final project and her practice experience was instrumental in my success in negotiating my first position as an advanced practice nurse. Dr. Okoli helped me develop my final project and his expertise in statistical analysis was vital to the completion of this project. Thank you both for being an important part of this journey. 


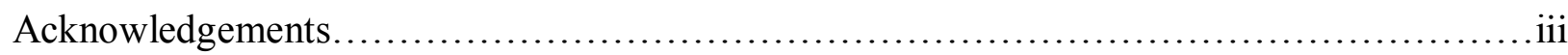

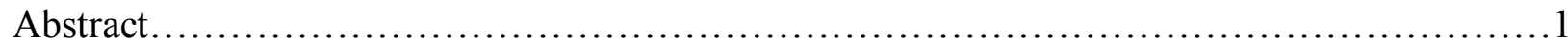

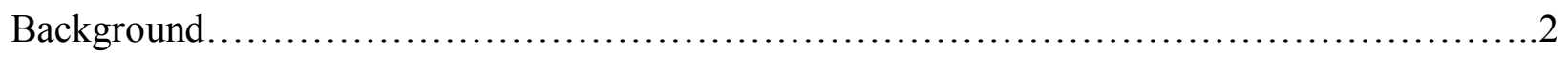

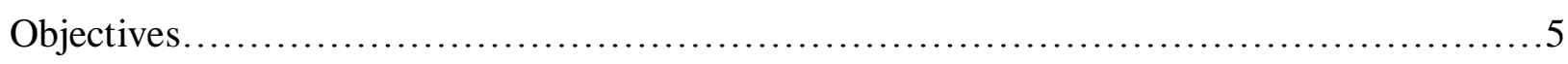

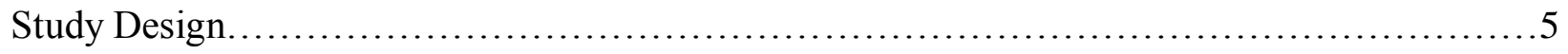

Study Population................................................................ 5

Subject Recruitment Methods and Privacy...........................................6

Data Analysis ................................................................. 7

Results........................................................................

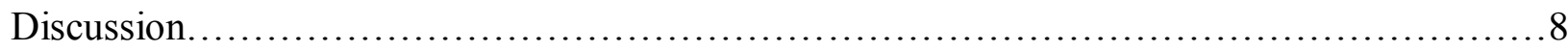

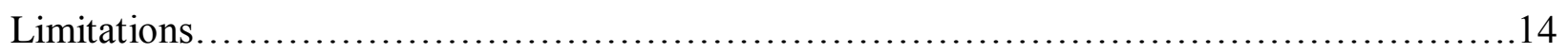

Conclusion.................................................................. 15

References........................................................................ 18

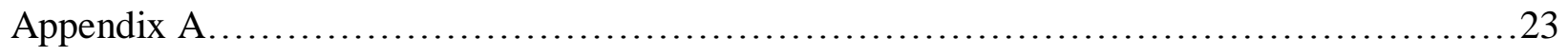

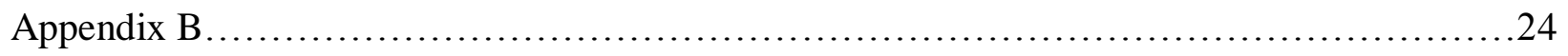

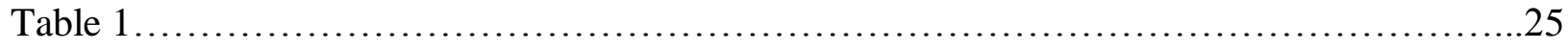

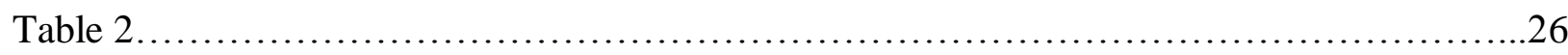




\begin{abstract}
In response to the problem of frequent 30 day re-admissions to inpatient psychiatric facilities, Vigod and colleagues (2015) developed the READMIT clinical risk index to identify risk factors for psychiatric inpatient re-admissions. The question addressed in this study was: Can the READMIT clinical risk index be used to identify patients that are at high risk for 30 day inpatient psychiatric re-admissions at Eastern State Hospital? This project used a descriptive retrospective design. Data were extracted from the discharge summaries of patients discharged from Eastern State Hospital between September 2013 and December 2014. Data collected included patient demographic variables (age, gender, race/ethnicity, primary diagnosis, housing status at discharge, employment, long acting injectable at discharge, substance abuse, education, and insurance status) and study variables from the READMIT clinical risk index (repeat admission, emergent admission, age, diagnosis and discharge, medical comorbidity, intensity, and time in hospital). The study population consisted of patients discharged from Eastern State Hospital between September 2013 and December 2014. The inclusion criterion was: ages 18 and above. There were no exclusion criteria. Findings indicated that age, insurance status, previous lifetime admissions, 'diagnoses and discharge' scores, and higher READMIT clinical risk index scores were associated with 30 day re-admissions at Eastern State Hospital. Future research should include a prospective study of the READMIT clinical risk index, a logistic regression evaluating its predictability of 30 day re-admissions, and an evaluation to establish the minimum clinical risk index score needed for patients to receive additional interventions post discharge.
\end{abstract}




\section{Background}

Although serious mental illness (SMI) only affects 5\% of the population, it is both costly and debilitating (Substance Abuse and Mental Health Services Administration [SAMHSA], 2010). According to SAMHSA (2010), a diagnosis of SMI is given to adults age 18 or older who:

At any time in the past year have had a diagnosable mental, behavioral, or emotional disorder (excluding developmental and substance use disorders) of sufficient duration to meet diagnostic criteria specified within DSM-IV (American Psychiatric Association [APA], 1994) that has resulted in serious functional impairment, which substantially interferes with or limits one or more major life activities (p. 9).

The most commonly diagnosed SMIs in the U.S. include schizophrenia spectrum disorders (schizophrenia and schizoaffective disorders), bipolar disorder, and major depressive disorder. The financial burden of treatment for SMI in the U.S. is considerable. Medicaid spending on mental health services is almost $30 \%$ of the total mental health expenditures in the U.S. (SAMHSA, 2010). The estimated annual cost of direct care treatments for patients with schizophrenia is in excess of $\$ 23$ billion (Wu et al., 2005), and schizophrenia only accounts for $1 \%$ of the U.S. population (APA, 2013; Wu et al., 2005). Annual total direct and indirect costs for SMI approach \$320 billion (National Institute of Mental Health [NIMH], 2002).

People diagnosed with SMIs are vulnerable to poor physical health and poor long-term health outcomes. Poor health in this population has been attributed to adverse effects of treatment for SMIs; for example, use of antipsychotic medications in the treatment of schizophrenia has been linked to higher rates of metabolic and cardiovascular disorders and 
obesity compared to the general population (McEvoy et al., 2005; De Hert et al., 2011). In addition, physical health outcomes among those with SMIs are poor due to limited accessibility to medical treatment and low rates of engagement in health-and illness-related behaviors. Research suggests that patients with SMI are at risk for higher rates of mortality and morbidity compared to the general population (Holt \& Peveler, 2010; Laursen et al., 2007; McEvoy et al., 2005). Their morbidity rate is almost $30 \%$ higher than the general population (NIMH, 2014).

Overall, persons with SMI have an average life span 15 years shorter than those living without SMI (Ringen, Engh, Birkenaes, Dieset, \& Andreassen, 2014) and are at increased risk for suicide (NIMH, 2014).

Optimal patient outcomes for both psychiatric and medical illnesses in this population depend on the patient's adherence to outpatient treatment. In an effort to improve psychiatric and medical outcomes and control costs, SAMHSA (2015) has endorsed the National Behavioral Health Quality Forum (NBHQF) as a means to identify and bridge current gaps in care. Two NBHQF goals are of critical importance to patient outcomes in the inpatient psychiatric care setting; these include NBHQF Goal 3, 'coordinated care' and NBHQF Goal 6, 'affordable/accessible care'. Currently at Eastern State Hospital in Lexington, Kentucky, only $30 \%$ of discharged patients attend their follow up appointments in the community mental health setting (A. Cooley, personal communication, February 10, 2015). Although follow up appointments are scheduled at time of discharge, patients often get lost in the transition of care from inpatient hospital to the outpatient community. Patients fail to attend their follow-up outpatient appointments for a variety of reasons, including lack of transportation, lack of family support, homelessness, substance abuse, and denial of illness or the need for treatment (Hamilton et al., 2015; Prince, 2006). 
The lack of care coordination between inpatient and outpatient settings following discharge often results in symptom relapse, which precipitates the need for another psychiatric inpatient admission soon after discharge. Frequent rehospitalizations are costly to the mental health services system (Heslin \& Weiss, 2015). SAMHSA addresses this issue in NBHQF Goal 6, affordable/accessible care, which aims to reduce the number of 30 day re-admissions to inpatient psychiatry post-discharge. In order to provide appropriate interventions during the transition of care and to optimize resource allocation, those most at risk for inpatient psychiatric re-admissions must be identified. As Eastern State Hospital works to develop a gap care transition team to reduce the risk for re-admission, it is critical that patients in need of transitional care are identified prior to discharge.

In response to the problem of frequent re-admissions to inpatient psychiatric facilities, Vigod and colleagues (2015) developed the READMIT clinical risk index to identify risk factors for re-admission. The READMIT clinical risk index assigns a clinical risk index score (0 to 41) for re-admission based on several criteria, including repeat admission, emergent admission, age, diagnosis and discharge, medical comorbidity, intensity, and time in hospital. To date, there have not been any published studies that have applied the READMIT clinical risk index to identify those at risk for 30 day re-admissions. Using the READMIT index to identify high risk patients may be useful in determining patients who should be prioritized for both inpatient and outpatient interventions to enhance continuity of care and reduce re-admissions. 


\section{Objectives}

The objectives of this project are:

1. To identify key variables that distinguish patients that are likely to be readmitted within 30 days post discharge, and

2. To evaluate the association between the READMIT clinical risk index scores and readmissions.

Specifically, the question that will be addressed in this study is: Can the READMIT clinical risk index be used to identify patients that are at high risk for inpatient psychiatric re-admissions at Eastern State Hospital?

\section{Study Design}

This project used a descriptive retrospective design. Data were extracted from the discharge summaries of patients discharged from Eastern State Hospital between September 2013 and December 2014. Data collected included patient demographic variables (age, gender, race/ethnicity, primary diagnosis, housing status at discharge, employment, long acting injectable at discharge, substance abuse, education, and insurance status) and study variables from the READMIT clinical risk index (repeat admission, emergent admission, age, diagnosis and discharge, medical comorbidity, intensity, and time in hospital).

\section{Study Population}

The study population consisted of patients discharged from Eastern State Hospital between September 2013 and December 2014. The inclusion criterion was: ages 18 and above. There were no exclusion criteria. 


\section{Subject Recruitment Methods and Privacy}

Eastern State Hospital is a psychiatric hospital that was founded in 1824, making it the second oldest psychiatric hospital in the country. A new 239 bed facility was opened in 2013. Eastern State serves Fayette and 50 other surrounding counties. The types of services offered are adult inpatient psychiatric treatment, both acute and long-term, specialized services for individuals with acquired brain injuries, long-term care for those with psychiatric disabilities requiring nursing facility level of care, and personal care homes. A letter of support was obtained from the medical director and senior nurse administrator to conduct this study.

Medical records from September 2013 to December 2014 were reviewed. The number of discharged patients between September 2013 and December 2014 was identified by the medical records supervisor as 2800 . The medical records department provided 2,000 discharge summaries for review. However, 1205 consecutive records were selected based on convenience for this study. Data were extracted from each discharge summary by the principal investigator using the patient demographic variable form (Appendix A) and the READMIT clinical risk index form (Appendix B). All discharge summaries were reviewed on site in a locked private office at Eastern State Hospital. SPSS was used to build a database that reflects the patient demographic variable form (Appendix A) and the READMIT clinical risk index form (Appendix B). Data were entered directly into an SPSS database on a password protected laptop. All discharge summaries had the patient names redacted by the medical records department at Eastern State Hospital. The principal investigator followed the HIPAA rules and regulations. A waiver of documentation of informed consent was obtained. The study was approved by the University of Kentucky Institutional Review Board. 


\section{Data Analysis}

Of 1205 selected discharge summaries only 1152 had calculable risk scores and were included for further analysis. Descriptive analyses using frequencies for categorical variables and means (and standard deviations) for continuous variables were used to describe patient demographic variables. Chi squared tests and t tests (with Levene's test for equality of variance, verified by Kruskal-Wallis tests as necessary) were used to describe differences in demographic variables between patients who were and were not 30 day return admissions. A significance level of $\mathrm{p} \leq .05$ was used in all analyses. All analyses were completed by using IBM SPSS Statistics version 22 .

\section{Sample Characteristics}

\section{Results}

The total sample is comprised of a majority of male (56\%) and Caucasian (89\%) patients, mostly between $35-46$ years of age (56\%). Participants were educated with $67 \%$ having a high school education or higher; however, they were mostly unemployed (92\%). The majority of participants were insured (80\%) and were discharged to their homes $(72 \%)$ at the end of their hospital stay. Although the majority of participants had "other" (e.g. adjustment disorder, anxiety disorder, post-traumatic stress disorder) psychiatric diagnoses at admission, a minority had psychosis or bipolar disorder (36\%) and depression (10\%). The majority of participants had either a current $(42 \%)$ or past $(20 \%)$ history of substance use. Participants who were readmitted within 30 days were significantly younger and were more likely to have insurance as compared to those who were not readmitted within 30 days. No other significant demographic differences were observed between groups (Table 1). 


\section{Differences in READMIT Index Scores by 30 Day Re-admission}

The READMIT Clinical Risk Index item scores differences by 30 day re-admission groups are noted in Table 2. The mean READMIT score for the sample was 20.0 ( $\mathrm{SD}=4.2)$. As compared to those not readmitted within 30 days, those who were readmitted in 30 days had significantly higher repeat admission scores ( $M=5.7$ vs. $M=3.4, p<.0001)$, suggesting that, on average, those with three to five previous admissions are at higher risk for 30 day re-admission. Age was also found to be a risk factor, with a mean risk score of $M=6.3$ in the readmitted group versus $\mathrm{M}=5.8$ in the non-readmitted group, $(\mathrm{p}=.008)$. Moreover, sample characteristics indicate that patients ages 18-34 were more likely to be re-admitted. Hence, younger patients are at greater risk for re-admissions. 'Diagnosis and discharge' score was an additional risk factor, $(\mathrm{M}=4.5$ vs. $\mathrm{M}=3.9, \mathrm{p}=.006)$; this score is a combination of primary diagnosis, personality disorder, and unplanned discharge. Sample characteristics indicate that the most common diagnoses scored were "other", psychosis/bipolar, and depression. Patients readmitted also had higher mean readmit risk scores ( $\mathrm{M}=23.3$ vs. $\mathrm{M}=19.9, \mathrm{p}<.0001)$.

\section{Discussion}

The purpose of this study was to identify key variables associated with 30 day inpatient psychiatric re-admissions and to evaluate the associations between the READMIT clinical risk index scores and re-admissions. Salient variables associated with 30 day re-admission were identified. However, due to sample limitations, the utility of the READMIT clinical risk index could not be fully explored.

Substance abuse, gender, ethnicity, education, use of a long acting injectable, employment and housing status at discharge were not associated with 30 day re-admissions. Although Vigod et al. (2015) did not exam the use of long acting injectables, the authors' other 
findings were consistent with the findings from this study. The current literature indicates variable support for each of these findings. Unemployment (Hamilton et al., 2015; Schmutte, Dunn, \& Sledge, 2010) has been found to be predictive of re-admissions. However, Webb, Yaguez, and Langdon (2007) found only three variables to be predictive for re-admissions ( $\mathrm{n}=$ 133): age at first admission, age at most recent admission, and affective disorder. The authors found no significant differences in ethnicity, gender, housing status and unemployment. Further, Stein et al. (2014) did not include housing status or employment, but found no statistical significance with regards to age, gender, and ethnicity.

The study findings included that higher READMIT clinical risk index scores were associated with 30 day re-admissions. Additionally, higher scores for lifetime admission, younger age, and higher scores for 'diagnoses and discharge' were also associated with 30 day re-admissions. Findings also indicate that having insurance was associated with 30 day readmissions. The current literature supports higher lifetime re-admission rates (Bowersox, Saunders, \& Berger, 2007; Montgomery \& Kirkpatrick, 2002; Schmutte, Dunn \& Sledge, 2009; Stein et al., 2014), and the diagnoses of psychosis (Hamilton et al., 2015; Lin et al., 2010; Schmutte, Dunn \& Sledge, 2010; Vigod et al., 2015), bipolar disorder, depression and other disorder (Bartholomew \& Zechner, 2014; Hamilton et al., 2015; Vigod et al., 2015) as being associated with inpatient psychiatric re-admissions. The associations between the diagnoses and increased re-admissions support the finding in this study of higher 'diagnoses and discharge' scores associated with 30 day re-admissions.

\section{Previous Admissions}

In this study, previous re-admissions were a significant risk for 30 day re-admissions. Previous re-admissions have been a long standing (Appleby et al., 1993; Mortensen \& Eaton, 
1994) and widely accepted risk factor (Hamilton et al., 2015; Lin et al., 2010; Vigod et al., 2015).

The READMIT clinical risk index indicates an increase in score based on the number of lifetime admissions. No previous lifetime admissions is a score of 0 points, one to two lifetime admissions is a score of 2 points, three to five admissions is a score of 5 points, and six or more admissions is a score of 7 points. Lifetime admissions may be the single most modifiable risk factor for persons with SMI.

Successful transition from inpatient to outpatient services is paramount to establishing a continuum of care and preventing re-admissions. Representatives from Eastern State Hospital have indicated that only $30 \%$ of discharged patients are adherent to their outpatient follow up appointment. The reasons why are not well understood, but could include lack of effective discharge planning, chronicity and severity of mental illness, logistic challenges such as transportation, and anosognosia. Bridge programs that provide transitional care from discharge until the completion of the first outpatient appointment could be an important step in reducing both 30 day re-admissions and lifetime re-admission rates. An implication for future research is a qualitative study to examine the reasons for inpatient re-admissions from the patients' perspective. The health belief model could provide a theoretical framework to help clinicians design interventions specific to the patients' needs and level of readiness to participate in services.

Age

Findings from this study indicate that younger age is a risk factor for re-admission. Age is a non-modifiable risk factor and speaks to the importance of early intervention and transitional services for young people. The age of onset for most mental illness is late adolescence and early adulthood (American Psychiatric Association [APA], 2013). However, symptoms of 
schizophrenia and bipolar disorders are often missed and result in a delay of treatment (Birchwood et al., 2013; Patel et al., 2015). Delay of treatment and lack of outpatient care increase the likelihood of inpatient psychiatric admissions.

The READMIT clinical risk index scores 'age' from 0 to 8 points, stratified by age group. For instance, an eight point score corresponds to the ages of 18-24 and 0 points are scored when older than 94 . The higher risk scores with younger age not only reflect the challenges associated with managing onset of a mental illness, but may also speak to the severity of illness. Eastern State Hospital is a state psychiatric facility and patients that are refractory to treatment, nonadherent to the plan of care, or in some cases violent, are often referred to Eastern State Hospital from other organizations. Understanding the unique challenges of treatment and illness management for the high risk age groups is important for future program development.

\section{Insurance Status}

The presence of insurance as an associated risk factor for 30 day re-admissions suggests that readmitted patients have been living with mental illness for some time and that they are not new to treatment. Being insured may also speak to the severity of illness and level of disability. In this study, $91.8 \%$ of 30 day re-admissions were insured. However, type of insurance was not measured. It may be worth exploring if there are differences between those patients who are insured by Medicaid versus Medicare versus commercial insurance. Medicaid has been identified as a predictor of psychiatric re-admissions (Druss, Bruce, Jacobs, \& Hoff, 1998; Smith, Stocks, \& Santora, 2015) and missed first outpatient appointments (Kruse, Rohland, \& Wu, 2002). The most recent data from Eastern State Hospital indicate that Medicaid coverage only accounts for $3.5 \%$ of insurance coverage (Z. Okoli, personal communication, March 31, 2016). 
Are patients returning because of access to care issues related to a shortage of providers accepting Medicaid? Is there a preference for inpatient care among insured patients? Are insured patients being discharged too soon, lacking the stability to follow through with outpatient care? Future research should include an evaluation of the current discharge process at Eastern State Hospital and the lived experiences of insured patients in accessing care, insight to current illness, and treatment preferences.

\section{Diagnosis and Discharge Score}

The 'diagnosis and discharge score' combines the risk score for diagnosis, personality disorder, and an unplanned discharge (left against medical advice). The READMIT clinical risk index scores psychosis and bipolar the highest with a point value of 4 . Next, the diagnosis of 'other', which includes all other diagnoses with the exceptions of depression and substance abuse, is point value of 3 . Depression is a point value of 2 and substance abuse is a point value of 0 . The presence of any personality disorder is a point value of 2 and an unplanned discharge is a point value of 5. The majority of patients in this study were diagnosed with 'other', but there were no associations found between groups based on diagnoses. However, the 'diagnosis and discharge score' was found to be higher in the 30 day re-admission group. There were few patients that left against medical advice in this sample, the higher scores suggest that the presence of a personality disorder in conjunction with one of the top three diagnoses is a significant risk factor.

\section{READMIT Clinical Risk Index Scores}

Vigod et al. (2015) developed and validated the READMIT clinical risk index, a one point increase in score was found to increase the odds of 30 day re-admissions by $11 \%$. They describe the index as having "moderate discriminatory capacity" with the expected probability of 
30 day re-admissions ranging from $2 \%$ with a score of 0 and $49 \%$ with a score of 41 . To date, there has not been a published application of the READMIT Clinical Risk Index or an additional validation of the index. In this study, higher index scores were associated with 30 day readmissions $(\mathrm{p}<.0001)$. However, a minimum cut score to screen people in for additional services has not been established. Findings in this study suggest that a score greater than 20 might be an indicator for additional services.

\section{Organizational Context}

The challenge for clinicians is not only in the evaluation of emerging evidence, but also the evaluation of the cultural and organizational context of these studies. The READMIT clinical risk index was found to be predictive based on the analysis of a national Canadian database $(n=32,749)$. Other researchers studied cohorts from a Veterans Affairs mental health system, n=233 (Bowersox, Saunders, \&Berger, 2011), inpatient psychiatric unit in Texas, $n=588$ (Hamilton et al., 2015), Medicaid claims data, n=11,801 (Stein et al., 2014), public-private mental health system in Connecticut, $\mathrm{n}=150$ (Schmutte, Dunn, \& Sledge, 2010), and an acute psychiatric ward in London, n=133 (Webb, Yaguez, \& Langdon, 2007). Lin et al. (2010) controlled for previous admissions and the study was conducted in Taiwan, $n=44,237$. The predictors for re-admission included male gender, poverty, hospital stay greater than 15 days, and a discharge diagnosis of schizophrenia or affective disorders (Lin et al., 2010). Each study included different variables, varied in methodology, did not all specifically target 30 day readmissions, and were conducted in different cultural and organizational systems. All of which make the external validity of the findings difficult.

Further, the organizational structure of the current study site must be taken into consideration. Before implementing evidenced based programs, clinicians need to evaluate 
current procedures, assess the level of current collaboration among inpatient providers within and outside of the organization, and understand limitations within the organization itself. Organizational limitations such as paper charting, employee turnover, and competing organizational interests can have a negative effect on available resources for researchers and the organizational readiness for practice improvement.

The implications for practice are that pilot studies with emerging evidence need to be conducted within a given system before they are adopted as best practice. Preliminary data from this current study suggest that the READMIT clinical risk index is worth exploring as a screening tool at Eastern State Hospital. Future research should include a prospective study of the READMIT clinical risk index, a logistic regression evaluating its predictability of 30 day readmissions, and an evaluation to establish the minimum clinical risk index score needed in order for patients to receive additional interventions post discharge.

\section{Implications for the Doctorally Prepared Nurse Practitioner}

The implications for the doctorally prepared nurse practitioner are in gaining a global view where practice, organizational and systems leadership, emerging evidence, policy, and scholarship converge in order to improve population health and encourage program development (Essential VIII; American Association of Colleges of Nursing [AACN], 2006). The essentials of doctoral education provide the framework for this study:

I. Scientific Underpinnings for Practice

II. Organizational and Systems Leadership for Quality Improvement and Systems Thinking

III. Clinical Scholarship and Analytical Methods for Evidence-Based Practice

IV. Information Systems/Technology and Patient Care Technology for the Improvement and Transformation of Health Care 
V. Health Care Policy for Advocacy in Health Care

VI. Interprofessional Collaboration for Improving Patient and Population Outcomes

VII. Clinical Prevention and Population Health for Improving the Nation's Health

VIII. Advanced Nursing Practice (AACN, 2006).

The READMIT clinical risk index is a first step in clinical prevention and improving population health for persons with SMI (Essential VII). This study provides the preliminary data (Essential I \& III) needed to move forward with research that implements the READMIT clinical risk index as a screening index to identify the most at risk patients for 30 day re-admissions at Eastern State Hospital.

Implications for future research are to develop intensive transitional care programs that bridge the gap in care from discharge to first outpatient appointment; further, qualitative research must be included to better understand the care seeking behaviors of persons that return within 30 days of discharge. Examining the impact that the type of insurance has on care seeking behaviors and 30 day re-admissions is also an important indicator to the success of future program development. Because the original READMIT study (Vigod et al., 2015) was based in Canada, which has a universal coverage system, insurance type was not relevant. However, type of insurance might be an additional pertinent risk factor in the U.S., which should be included in a modified clinical risk index for 30 day re-admissions. Understanding the implications of insurance re-imbursement on patients, providers, and organizations provide clinicians the needed tools to advocate for policy changes in health care (Essential V). For instance, is the shortage of Medicaid providers impacting persons with SMI ability to access outpatient care?

Additionally, the organizational context must be considered as new programs are being developed (Essential VI). Is there collaboration within the organization? Does the organization 
collaborate with outpatient services? Does the organization ensure that the patient discharge needs are met, and that the patient understands the discharge plan? Do staff members within the organization communicate with the patient regarding the discharge plan (Essential VIII)? Are there competing interests within the organization? Does the organization have the technology to support research and program development (Essential IV)?

\section{Limitations}

The main limitations for this study were lack of generalizability of findings due to convenience sampling methods and time constraints. Specifically, two thousand nonrandomized discharge summaries from September 2013 to December 2014 were provided by the organization to the principal investigator. Because the records were non-randomized it is not possible to conclude that there were non-systematic differences in patients derived for the sample. Moreover, due to time constraints, only 1205 (i.e. $60 \%$ ) were selected for the study. Finally, due to sample limitations, logistic regressions analyses to establish if the READMIT clinical risk index was predictive of 30 day re-admission at Eastern State Hospital was not possible. Despite these limitations, findings have advanced an understanding of risk factors that clinicians need to target to avoid 30 day hospital re-admission and further suggest that the READMIT tool may be a useful strategy for identifying those at risk.

\section{Conclusion}

In order to determine the utility of the READMIT clinical risk index future research is needed. The trend in the available data indicate that the READMIT clinical risk index may be useful as a screening tool to help identify patients that are at risk for 30 day re-admissions. An evidence based screening index that identifies patients with a quantifiable risk score is needed in order to effectively develop programs that help with the transition from inpatient to outpatient 
care in the community (Vigod et al., 2015). In addition, a qualitative study may further elucidate challenges and barriers to transitioning to the outpatient treatment from the patients' perspective. 


\section{References}

American Association of Colleges of Nursing. (2006). The essentials of doctoral education for advanced nursing practice. Washington, DC: Author.

American Psychiatric Association. (1994). Diagnostic and statistical manual of mental disorders (4 ${ }^{\text {th }}$ ed.). Washington, DC: Author.

American Psychiatric Association. (2013). Diagnostic and statistical manual of mental disorders $\left(5^{\text {th }}\right.$ ed.) Arlington, VA: American Psychiatric Publishing

Appleby, L., Desai, P., Luchins, D., Gibbons, R., Janicak, P., \& Marks, R. (1993). Length of stay and recidivism in schizophrenia: A study of public psychiatric hospital patients. American Journal of Psychiatry, 150, 72-25.

Bartholomew, T., \& Zechner, M. (2014). The relationship of illness management and recovery to state hospital readmission. The Journal of Nervous and Mental Disease, 202(9), 647-650. doi: 10.1097/NMD.0000000000000177

Birchwood, M., Connor, C., Lester, H., Patterson, P., Freemantle, N., Marshall, M., ...Singh, S. (2013). Reducing duration of untreated psychosis: care pathways to early intervention in psychosis services. British Journal of Psychiatry, 203(1), 58-64. doi: 10.1192/bjp.bp.112.125500

Bowersox, N., Saunders, S., \& Berger, B. (2011). Predictors of rehospitalization in highutilizing patients in the VA psychiatric medical system. Psychiatric Quarterly, 83, 5362. doi: 10.1007/s11126-011-9182-2

DeHert, M., Correll, C., Bobes, J., Cetkovich-Bakmas, M., Cohen, D., Asai, I., ...Leutch, S. (2011). Physical illness in patients with severe mental disorders. I. Prevalence, impact of medications and disparities in health care. World Psychiatry, 10(1), 52-77. 
Druss, B., Bruce, M., Jacobs, S., \& Hoff, R. (1998). Trends over a decade for a general hospital psychiatry unit. Adm Policy Ment Health, 25(4), 427-435.

Hamilton, J. E., Rhoades, H., Galvez, J., Allen, M., Green, C., Aller, M., \& Soares, J. C. (2015). Factors differentially associated with early re-admission at a university teaching psychiatric hospital. J Eval Clin Pract. doi: 10.1111/jep.12335

Heslin K., \& Weiss A. (2015, May). Hospital Readmissions Involving Psychiatric Disorders, 2012 (HCUP Statistical Brief \#189). Retrieved from Agency for Healthcare Research and Quality website: http://www.hcup-us.ahrq.gov/reports/statbriefs/sb189-HospitalReadmissions-Psychiatric-Disorders-2012.pdf.

Holt, R., \& Peveler, R. (2010). Diabetes and cardiovascular risk in SMI: a missed opportunity and challenge for the future. Practical Diabetes Int, 27(2), 79-84ii.

Kruse, G., Rohland, B., \& Wu, X. (2002). Factors associated with missed first appointments at a psychiatric clinic. Psychiatric Serv, 53(9), 1173-1176.

Laursen, T., Munk-Olsin, T., Nordentoft, M., \& Mortenson, P. (2007). Increased mortality among patients admitted with major psychiatric disorders: a register-based study comparing mortality in unipolar depressive disorder, bipolar affective disorder, schizoaffective disorder, and schizophrenia. Journal of Clinical Psychiatry, 68(6), 899907.

Lin, C., Chen, W., Lin, C., Lee, M., Ko, M., Li, C. (2010) Predictors of psychiatric readmissions in the short and long term: A population-based study in Taiwan. Clinical Science, 65(5), 481-489. doi: 10.1590/S1807-59322010000500005

McEvoy, J., Meyer, J., Goff, D., Nasrallah, H., Davis, S., Sullivan, L., ...Lieberman, J. (2005). Prevalence of the metabolic syndrome in patients with schizophrenia: baseline results 
from the Clinical Antipsychotic Trials of Intervention Effectiveness (CATIE)

schizophrenia trial and comparison with national estimates from NHANES III.

Schizophrenia Bulletin, 80(1), 19-32. doi: http://dx.doi.org/10.1016/j.schres.2005.07

.014

Montgomery, P., \& Kirkpatrick, H. (2002). Understanding those who seek frequent psychiatric hospitalizations. Archives of Psychiatric Nursing, 16(1), 16-24. doi:

10.1053/apnu.2002.30494

Mortensen, P., \& Eaton, W. (1994). Predictors of readmission risk in schizophrenia. Psychol Med, 187, 721-729.

National Institute of Mental Health. (2002). Annual total direct and indirect costs of serious mental illness. Retrieved from http://www.nimh.nih.gov/ health/statistics/ cost/index.shtml

National Institute of Mental Health. (2014). Suicide in America. Retrieved from http://www.nimh.nih.gov/health/publications/suicide-in-america/index.shtml

Patel, R., Shetty, H., Jackson, R., Broadbent, M., Stewart, R., Boydell, J., ... Taylor, M. (2015). Delays before Diagnosis and Initiation of Treatment in Patients Presenting to Mental Health Services with Bipolar Disorder. PLoS ONE, 10(5), e0126530. http://doi.org/10.1371/journal.pone.0126530

Prince, J. D. (2006). Practices preventing rehospitalization of individuals with schizophrenia. $J$ Nerv Ment Dis, 194(6), 397-403. doi: 10.1097/01.nmd.0000222407.31613.5d

Ringen, P. A., Engh, J. A., Birkenaes, A. B., Dieset, I., \& Andreassen, O. A. (2014). Increased mortality in schizophrenia due to cardiovascular disease - a non-systematic review of 
epidemiology, possible causes, and interventions. Front Psychiatry, 5, 137. doi: 10.3389/fpsyt.2014.00137

Schmutte, T., Dunn, C., \& Sledge, W. (2009). Characteristics of inpatients with a history of recurrent psychiatric hospitalizations: A matched control study. Psychiatric Services, 60(12), 1683-1685.doi:10.1176/appi.ps.60.12.1683

Schmutte, T., Dunn, C., \& Sledge, W. (2010). Predicting time to readmission in patients with recent histories of recurrent psychiatric hospitalizations. The Journal of Nervous and Mental Disease, 198(12), 860-863.

Smith, M., Stocks, C., \& Santora, P. (2015). Hospital readmission rates and emergency department visits for mental health and substance abuse conditions. Community Mental Health Journal, 51(2), 190-197. doi: 10.1007/s10597-014-9784-x

Stein, B., Pangilinan, M., Sorbero, M., Marcus, S., Donahue, S., Xu, Y.,...Essock, S. (2014). using claim data to generate clinical flags predicting short-term risk of continued psychiatric hospitalizations. Psychiatric Services, 65(11), 1341-1346. doi: 10.1176/appi.ps.201300306

Substance Abuse and Mental Health Services Administration. (2010). Results from the 2010 NationalSurvey on Drug Use and Health: Mental Health Findings, NSDUH Series H42, HHSPublication No. (SMA) 11-4667. Rockville, MD: Substance Abuse and Mental Health ServicesAdministration

Substance Abuse and Mental Health Services Administration. (2015). National behavioral health quality forum. Retrieved from http://www.samhsa.gov/data/national-behavioralhealth-quality-framework 
Vigod, S. N., Kurdyak, P. A., Seitz, D., Herrmann, N., Fung, K., Lin, E., . . . Gruneir, A. (2015). READMIT: a clinical risk index to predict 30 day re-admission after discharge from acute psychiatric units. J Psychiatr Res, 61, 205-213. doi:

10.1016/j.jpsychires.2014.12.003

Webb, S., Yaguez, L., \& Langdo, P. (2007). Factors associated with multiple re-admission to a psychiatric hospital. Journal of Mental Health, 16(5), 647-661. doi:

$10.1080 ? 09638230701494845$

Wu, E. Q., Birnbaum, H. G., Shi, L., Ball, D. E., Kessler, R. C., Moulis, M., \& Aggarwal, J. (2005). The economic burden of schizophrenia in the United States in 2002. J Clin Psychiatry, 66(9), 1122-1129. 


\section{Appendix A}

Patient Demographic Variable Collection Form

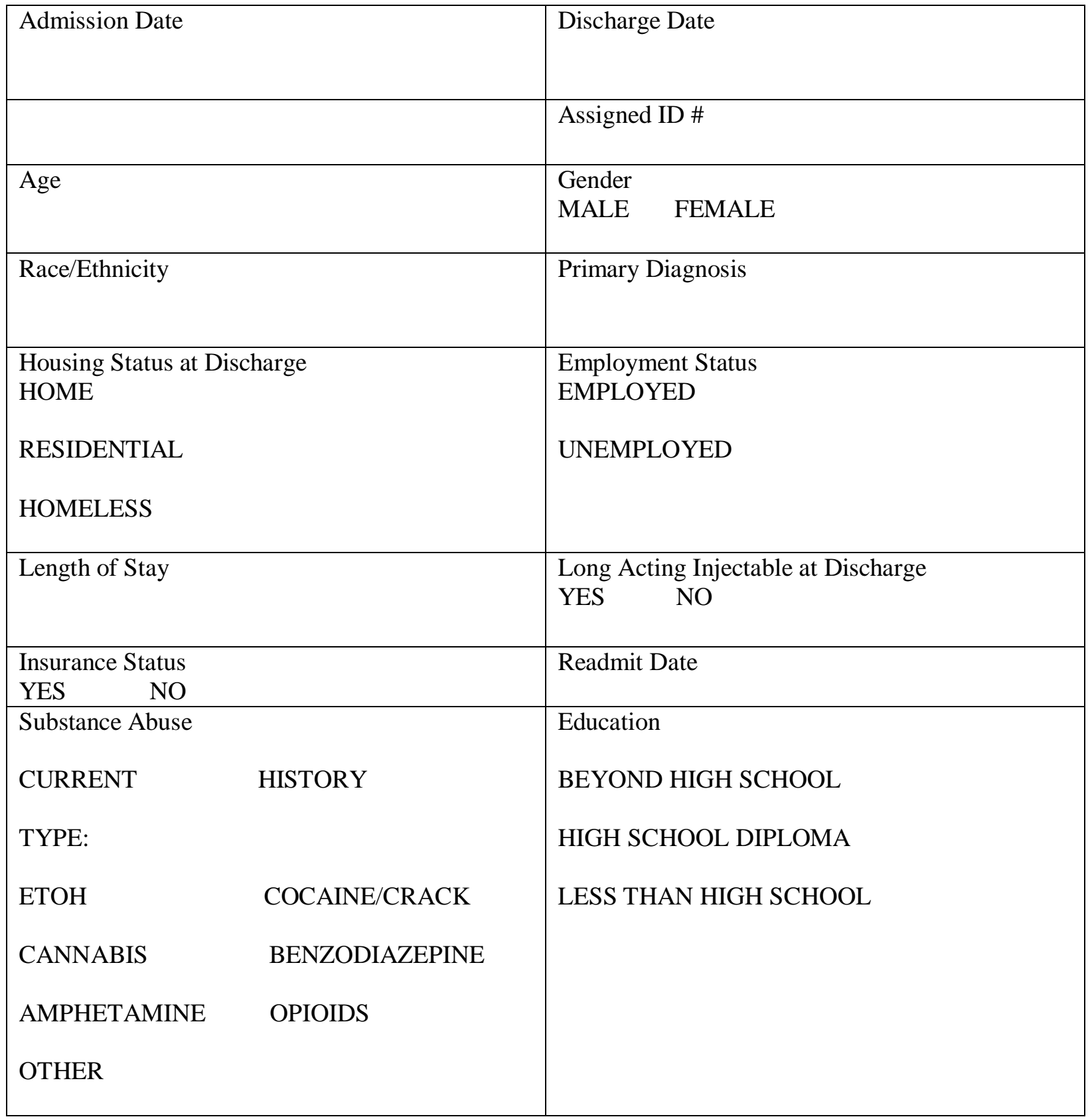




\section{Appendix B \\ READMIT Clinical Risk Index Form}

\begin{tabular}{|c|c|c|c|}
\hline Risk factor & Variable & Value & Points \\
\hline \multirow[t]{4}{*}{ "R" - Repeat admission (lifetime) } & Number prior to index & 0 & 0 \\
\hline & & 1 to 2 & 2 \\
\hline & & 3 to 5 & 5 \\
\hline & & 6 or more & 7 \\
\hline \multirow[t]{6}{*}{$-\tau^{\prime}$ - Emergent admission } & Threat to others & No & 0 \\
\hline & & Yes & 1 \\
\hline & Threat to self & No & 0 \\
\hline & & Yes & 1 \\
\hline & Unable to care for self & No & 0 \\
\hline & & Yes & 2 \\
\hline \multirow[t]{9}{*}{ "A" - Age } & Age group (years) & Older than 94 & 0 \\
\hline & & 85 to 94 & 1 \\
\hline & & 75 to 84 & 2 \\
\hline & & 65 to 74 & 3 \\
\hline & & 55 to 64 & 4 \\
\hline & & 45 to 54 & 5 \\
\hline & & 35 to 44 & 6 \\
\hline & & 25 to 34 & 7 \\
\hline & & 18 to 24 & 8 \\
\hline \multirow[t]{8}{*}{ "D" - Diagnosis and discharge } & Primary diagnosis & Alcohol or substance & 0 \\
\hline & & Depression & 2 \\
\hline & & Psychosis or Bipolar & 4 \\
\hline & & Other & 3 \\
\hline & Any personality disorder & No & 0 \\
\hline & & Yes & 2 \\
\hline & Unplanned discharge & No & 0 \\
\hline & & Yes & 5 \\
\hline \multirow[t]{3}{*}{ "M" - Medical morbidity } & Charlson comorbidity score & 0 & 0 \\
\hline & & 1 to 2 & 1 \\
\hline & & 3 or more & 2 \\
\hline \multirow[t]{4}{*}{ "I" - Intensity (past year) } & Outpatient psychiatrist visits & Less than 2 & 0 \\
\hline & & 2 or more & 2 \\
\hline & Emergency departinent visits & None & 0 \\
\hline & & 1 or more & 3 \\
\hline \multirow[t]{3}{*}{ "T" - Time in hospital } & Length of stay (Days) & More than 28 days & 0 \\
\hline & & 15 to 28 & 3 \\
\hline & & Less than 14 & 4 \\
\hline Total possible score & & & 41 \\
\hline
\end{tabular}

${ }^{a}$ For Charlson comorbidity score, assign 1 point each for previous myocardial infarction, cerebrovascular disease, peripheral vascular disease, diabetes; 2 points each for heart failure, chronic obstructive pulmonary disease, mild liver disease, any tumor (including lymphoma or leukemia); 3 points each for dementia, connective tissue disease; 4 points each for AIDS and moderate or severe liver disease; and 6 points for metastatic solid tumour.

Source: Vigod, S. N., Kurdyak, P. A., Seitz, D., Herrmann, N., Fung, K., Lin, E., . . Gruneir, A. (2015). READMIT: a clinical risk index to predict 30 day re-admission after discharge from acute psychiatric units. J Psychiatr Res, 61, 205-213. doi:

10.1016/j.jpsychires.2014.12.003 
Table 1. Demographics by 30 Day Re-admission Status by Program Completion

\begin{tabular}{|c|c|c|c|c|c|c|c|}
\hline & \multicolumn{2}{|c|}{$\begin{array}{c}\text { Total } \\
(\mathrm{N}=1152)\end{array}$} & \multicolumn{2}{|c|}{$\begin{array}{c}30 \text { Day } \\
\text { Readmitted } \\
(\mathrm{n}=52)\end{array}$} & \multicolumn{2}{|c|}{$\begin{array}{l}\text { Not Readmitted } \\
\quad(n=1100)\end{array}$} & \multirow{2}{*}{$\begin{array}{c}\text { Difference* } \\
\begin{array}{c}\text { Chi-square, df } \\
\text { (P-value) }\end{array}\end{array}$} \\
\hline & $\mathrm{N}$ & $\%$ & $N$ & $\%$ & $n$ & $\%$ & \\
\hline Sex & & & & & & & $0.26,1(.608)$ \\
\hline Female & 505 & 43.8 & 21 & 40.4 & 484 & 44.4 & \\
\hline Male & 647 & 56.2 & 31 & 59.6 & 616 & 56.0 & \\
\hline Age & & & & & & & $7.27,2(.026)$ \\
\hline $18-34$ & 418 & 36.3 & 28 & 53.8 & 390 & 35.5 & \\
\hline $35-64$ & 645 & 56.0 & 21 & 40.4 & 624 & 56.7 & \\
\hline 65 and older & 89 & 7.7 & 3 & 5.8 & 86 & 7.8 & \\
\hline Ethnicity $($ missing= 3) & & & & & & & $1.20,3(.752)$ \\
\hline Caucasian & 1024 & 89.1 & 48 & 92.3 & 976 & 89.0 & \\
\hline African American & 103 & 9.0 & 4 & 7.7 & 99 & 9.0 & \\
\hline Hispanic & 7 & 0.6 & 0 & 0.0 & 7 & 0.6 & \\
\hline Other & 15 & 1.3 & 0 & 0.0 & 15 & 1.4 & \\
\hline Education Level $($ missing $=161)$ & & & & & & & $2.59,2(.274)$ \\
\hline Less than High School & 324 & 32.7 & 18 & 39.1 & 306 & 32.4 & \\
\hline High School/GED or greater & 345 & 34.8 & 18 & 39.1 & 327 & 34.6 & \\
\hline Beyond High School & 322 & 32.5 & 10 & 21.7 & 312 & 33.0 & \\
\hline Employment Status (missing= 42) & & & & & & & $3.02,1(.082)$ \\
\hline Employed & 94 & 8.5 & 1 & 1.9 & 93 & 8.8 & \\
\hline Unemployed & 1016 & 91.5 & 51 & 98.1 & 965 & 91.2 & \\
\hline Insurance Status $($ missing= 83) & & & & & & & $4.62,1(.032)$ \\
\hline Yes & 853 & 79.8 & 45 & 91.8 & 808 & 79.2 & \\
\hline No & 216 & 20.2 & 4 & 8.2 & 212 & 20.8 & \\
\hline $\begin{array}{l}\text { Housing Status at Discharge (missing= } \\
\text { 85) }\end{array}$ & & & & & & & $1.51,2(.469)$ \\
\hline Home & 767 & 71.9 & 39 & 79.6 & 728 & 71.5 & \\
\hline Residential & 177 & 16.6 & 6 & 12.2 & 171 & 16.8 & \\
\hline Homeless & 123 & 11.5 & 4 & 8.2 & 119 & 11.7 & \\
\hline Primary Diagnosis & & & & & & & $3.70,3(.295)$ \\
\hline Alcohol or substance & 106 & 9.2 & 3 & 5.8 & 103 & 9.4 & \\
\hline Depression & 120 & 10.4 & 2 & 3.8 & 118 & 10.7 & \\
\hline Psychosis or Bipolar & 417 & 36.2 & 22 & 42.3 & 395 & 35.9 & \\
\hline Other & 509 & 44.2 & 25 & 48.1 & 484 & 44.0 & \\
\hline Substance Use (missing= 27) & & & & & & & $2.91,2(.233)$ \\
\hline Current & 469 & 41.7 & 16 & 30.8 & 453 & 42.2 & \\
\hline Past History & 223 & 19.8 & 11 & 21.2 & 212 & 19.8 & \\
\hline None & 433 & 38.5 & 25 & 48.1 & 408 & 38.0 & \\
\hline Long Acting Injectable (missing= 3) & & & & & & & $.06,1(.801)$ \\
\hline Yes & 249 & 21.7 & 12 & 23.1 & 237 & 21.6 & \\
\hline No & 900 & 78.3 & 40 & 76.9 & 860 & 78.4 & \\
\hline
\end{tabular}

*Differences are calculated using chi-square analyses for categorical and ordered categorical values (with Fisher's exact test for cells with lower than expected cell count). 
Table 2. READMIT Clinical Risk Index Items by 30 Day Readmit Status

\begin{tabular}{|c|c|c|c|c|c|c|c|}
\hline & \multicolumn{2}{|c|}{$\begin{array}{c}\text { Total } \\
(\mathrm{N}=1152)\end{array}$} & \multicolumn{2}{|c|}{$\begin{array}{l}30 \text { Day Readmitted } \\
(\mathrm{n}=52)\end{array}$} & \multicolumn{2}{|c|}{$\begin{array}{l}\text { Not Readmitted } \\
\quad(\mathrm{n}=1100)\end{array}$} & \multirow{2}{*}{$\begin{array}{c}\text { Difference* } \\
\text { T-test, df (P-value) }\end{array}$} \\
\hline & $\mathrm{M}$ & SD & $\mathrm{M}$ & $\mathrm{SD}$ & M & SD & \\
\hline Repeat Admission (lifetime) & 3.5 & 2.6 & 5.7 & 1.8 & 3.4 & 2.6 & $42.7,1151(<.0001)$ \\
\hline Emergent Admission & 0.9 & 0.9 & 0.8 & 0.5 & 0.9 & 0.9 & $1.9,1151(.167)$ \\
\hline Age & 5.8 & 1.6 & 6.3 & 1.4 & 5.8 & 1.6 & 7.0, $1151(.008)$ \\
\hline Diagnosis and discharge & 4.0 & 1.4 & 4.5 & 1.1 & 3.9 & 1.4 & $7.4,1151(.006)$ \\
\hline Medical morbidity & 0.4 & 0.7 & 0.4 & 0.6 & 0.4 & 0.7 & $.21,1151(.645)$ \\
\hline Intensity (past year) & 2.1 & 1.5 & 2.3 & 1.7 & 2.1 & 1.4 & $.41,1151(.524)$ \\
\hline Time in hospital & 3.4 & 1.3 & 3.5 & 1.2 & 3.3 & 1.3 & $.39,1151(.530)$ \\
\hline Mean READMIT Score & 20.0 & 4.2 & 23.3 & 3.7 & 19.9 & 4.2 & $35.2,1151(<.0001)$ \\
\hline
\end{tabular}

*Differences are calculated using t test analyses (with Levene's test for equality of variance, verified by Kruskal-Wallis Tests as necessary). 